DOI: http://dx.doi.org/10.11606/issn.1984-4867.v27i2p388-413

\title{
Patrimônio Histórico Ambiental: diagnósticos para criação de unidade de conservação e orientações para o uso público do Jardim Botânico de Ouro Preto-MG
}

\section{Heritage Environmental History: diagnostics for creating conservation unit and guidelines for the public use of the Botanical Garden of Ouro Preto-MG}

\section{Patrimonio Historia Ambiental: diagnóstico para la creación de la unidad de conservación y las directrices para el uso público del Jardín Botánico de Ouro Preto-MG}

Simone Fernandes Machado ${ }^{1}$

Valéria da Conceição Chaves ${ }^{2}$

Ricardo Eustáquio Fonseca Filho ${ }^{3}$

\section{Resumo}

No final do século XVIII, na antiga Vila Rica (MG), foi definido um espaço, que em 1840, passou a abrigar uma escola de ensino prático de agricultura, transformando-se no Jardim Botânico de Ouro Preto-MG. Atualmente o local está sendo pleiteando para a criação de uma Unidade de Conservação (UC) Estadual. O presente trabalho foi realizado como parte dos estudos para avaliar a possibilidade de criação de uma nova UC nesta área em consonância com a Lei Federal n ${ }^{\circ}$. 9.985, de 18/07/2000. Para tanto, foram realizadas as seguintes etapas: revisão bibliográfica; levantamentos de dados secundários e primários provenientes de cinco visitas in loco, realizadas em novembro de 2014; análise de 40 entrevistas, realizadas com representantes institucionais, moradores e lideranças comunitárias formais e informais, de Ouro Preto. Como resultado obteve-se uma análise preliminar dos impactos e oportunidades oferecidas na criação da UC e o apontamento de sugestões para o estabelecimento da mesma. O estudo propôs ainda algumas orientações para o manejo da UC, através do desenvolvimento dos atrativos turísticos de base comunitária, que contam com elementos de referência histórica, cultural e ecoturística, propiciando a preservação do meio ambiente e o resgate da memória cultural e da identidade regional.

Palavras-chave: Unidade de Conservação; Uso público; Atrativo turístico.

\footnotetext{
1 Pós-graduanda em Engenharia Ambiental e em Direito Ambiental pela Instituto Prominas. Graduada em Turismo pela Universidade Federal de Ouro Preto (UFOP). Graduanda em Ciências Biológicas pela Universidade Federal de Ouro Preto (UFOP). Ouro Preto, Minas Gerais, Brasil. E-mail: simonexveiga1@yahoo.com.br

2 Mestra em Educação pela Universidade Federal Juiz de Fora (UFJF). Especialização em Educação Empreendedora pela Universidade Federal de São João del-Rei (UFSJ). Graduada em História pela Universidade Federal de Juiz de Fora (UFSJ). Bacharelado em Turismo pela Universidade Federal de Ouro Preto (UFOP). Ouro Preto, Minas Gerais, Brasil. E-mail: vacomchaves@yahoo.com.br

${ }^{3}$ Doutorando e Mestre em Evolução Crustal e Recursos Naturais pela Universidade Federal de Ouro Preto (UFOP). Graduado em Turismo pela Universidade Federal de Ouro Preto (UFOP). Professor do curso de Bacharelado em Turismo da Universidade Federal de Ouro Preto (UFOP). Ouro Preto, Minas Gerais, Brasil. Email: ricardoefonseca@gmail.com
} 


\begin{abstract}
In the late eighteenth century, in the old Vila Rica (MG), it was defined space, which in 1840 began to house a practical teaching agriculture school, becoming the Botanical Gardens Ouro Preto-MG. Currently the site is being pleading for the creation of a Conservation Unit (CU) State. This study was conducted as part of studies to assess the possibility of creating a new UC in this area in line with the Federal Law no. 9985 of 18/07/2000. Therefore, the following steps were taken: a literature review; secondary and primary data surveys from five site visits, held in November 2014; analysis of 40 interviews conducted with institutional representatives, residents and formal and informal community leaders, Ouro Preto. As a result we obtained a preliminary analysis of the impacts and opportunities in the creation of UC and pointing suggestions for the establishment of it. The study also proposed some guidelines for the management of UC through the development of community-based tourist attractions, which have historical reference elements, cultural and eco-tourism, promoting the preservation of the environment and the rescue of cultural memory and regional identity.
\end{abstract}

Keywords: Protected area; Public use; Tourist attraction.

\title{
Resumen
}

A finales del siglo XVIII, en la antigua Villa Rica $(M G)$, se define el espacio, que se inició en 1840 para albergar una escuela práctica la enseñanza de la agricultura, convirtiéndose en el Jardín Botánico de Ouro Preto-MG. Actualmente el sitio se está abogando por la creación de un Estado Unidad de Conservación (UC). Este estudio se llevó a cabo como parte de estudios para evaluar la posibilidad de crear un nuevo UC en esta área de acuerdo con la Ley Federal no. 9985 de 18/07/2000. Por lo tanto, se tomaron las siguientes medidas: una revisión de la literatura; levantamientos de datos secundarios y primarios de cinco visitas al sitio, que tuvo lugar en noviembre de 2014; análisis de 40 entrevistas realizadas a representantes institucionales, residentes y líderes formales e informales de la comunidad, de Ouro Preto. Como resultado se obtuvo un análisis preliminar de los impactos y oportunidades en la creación de la Universidad de California y sugerencias que apuntan para el establecimiento de la misma. El estudio también propone algunas directrices para la gestión de la UC a través del desarrollo de las atracciones turísticas basadas en la comunidad, que tienen elementos de referencia históricos, culturales y eco-turismo, promoviendo la preservación del medio ambiente y el rescate de la memoria cultural y la identidad regional.

Palabras clave: Áreas protegidas; Uso público; Atracción turística.

\section{Introdução}

O meio ambiente é direito fundamental que se origina da reação do homem frente às ameaças fundamentais que o circundam. Conforme Benjamin (2002, p. 93), "a constitucionalização do ambiente, ou seja, a elevação das normas de proteção ambiental ao status constitucional é considerada uma tendência mundial irreversível", dado o crescente número de nações que passaram a incluir em suas respectivas Cartas normas que regulamentam esta questão. Neste 
contexto, a Constituição Federal do Brasil de 1988 ostenta uma série de medidas que apontam para a crescente preocupação com a preservação do meio ambiente. De fato, a mesma traz preceitos quanto à tutela ambiental, seja de forma fragmentada como parte de um todo, seja em um capítulo específico (CAPÍTULO VI) que aborda, essencialmente, o "Meio Ambiente".

Os artigos 23 e 24, desta Constituição dispõem ainda que "é competência comum da União, dos Estados, do Distrito Federal e dos Municípios [...] proteger o meio ambiente e combater a poluição em qualquer de suas formas" (BRASIL, 1988, art. 23, VI), sendo responsabilidade comum a estas instâncias "legislar concorrentemente sobre [..] florestas, caça, pesca, fauna, conservação da natureza, defesa do solo e dos recursos naturais, proteção do meio ambiente e controle da poluição" (BRASIL, 1988, art. 24, VI), ou seja, zelar pela preservação das florestas, da fauna e da flora (BRASIL, 1988, art. 23, VII) em prol da conservação da natureza, da defesa do solo e dos recursos naturais, protegendo o meio ambiente, o patrimônio histórico, cultural, artístico, turístico e paisagístico (BRASIL, 1988, art. 24, VII); sendo responsabilizado pelos danos a eles provocados (BRASIL, 1998, art. 216, $\S 4^{\circ}$ ).

Ademais, a lei $\mathrm{n}^{\circ} .6 .938$ de 31 de agosto de 1981, com suas modificações subsequentes elenca, no art. $9^{\circ}$, treze instrumentos da Política Nacional do Meio Ambiente, dentre os quais prevê a criação de espaços territoriais especialmente protegidos pelo Poder Público federal, estadual e municipal, tais como áreas de proteção ambiental, de relevante interesse ecológico e reservas extrativistas.

$\mathrm{O}$ direito ao meio ambiente ecologicamente equilibrado consiste, por excelência, em um direito de interesse coletivo lato sensu, visto a pertencer a todos, nos termos do caput do art. 225 da Constituição Federal, de 1988. Os espaços territoriais especialmente protegidos estão previstos expressamente pelo art. 225, $\S 1^{\circ}$, III, desta Constituição, que discrimina o gênero aos quais as unidades de conservação, as áreas de preservação permanente e de reserva legal são especificadas. Assim, tais propósitos foram regulamentados posteriormente pela Lei 9.985/2000 que institui o Sistema Nacional de Meio Ambiente - SNUC. A Lei 9.985/2000 disciplinou os critérios para criação, implantação e gestão das Unidades de Conservação, encontrando-se regulamentada pelo Decreto $n^{\circ} 4.340$, de 22/08/2002, que define a Unidade de Conservação (UC), como sendo:

[...] espaço territorial e seus recursos ambientais, incluindo as águas jurisdicionais, com características naturais relevantes, legalmente instituído pelo Poder Público, com objetivos de conservação e limites definidos, sob 
regime especial de administração, ao qual se aplicam garantias adequadas de proteção (BRASIL, 2002, art. $2 .^{\circ}$, I).

Logo, o estabelecimento de áreas protegidas é de relevante interesse, para a manutenção das condições ambientais essenciais à vida. Nesse sentido, a instituição de uma UC pode estabelecer além da necessidade de conservação da fauna e flora, um espaço com objetivos de conservação delimitados legalmente. Para tanto, algumas questões apresentam-se diante desta situação, que pressupõem compreender quais são as áreas que se enquadram nos quesitos para se tornarem Unidades de Conservação, qual a percepção deste fato, pela comunidade do entorno destas áreas, bem como quais são os impactos (positivos e/ou negativos) que o registro de uma UC pode ocasionar no meio biótico e social. Tais questões compõem o relatório de dados necessários à realização do diagnóstico prévio, exigido para a criação da UC do Jardim Botânico de Ouro Preto-MG e que foram realizados nos momentos de atuação profissional junto ao Ministério Público do Estado, uma vez que esta pesquisa é apenas um recorte de um trabalho mais complexo, que vem sendo desenvolvido junto a esta instituição.

De posse destas informações, o presente trabalho visou realizar um diagnóstico dos aspectos de relevância social do Jardim Botânico de Ouro Preto-MG em consonância com a Legislação Federal vigente, SNUC, a fim de averiguar a viabilidade e os possíveis impactos sociais da criação de uma nova Unidade de Conservação Estadual na área.

\section{Metodologia do Estudo}

Por tratar-se de uma pesquisa focada principalmente no potencial e impacto referentes à implementação da atividade turística, propôs-se a utilização dos Métodos Qualitativos por propiciar a interpretação de elementos subjetivos da pesquisa, possibilitando uma análise mais dinâmica. Nesse sentido, Dencker destaca como características deste método a "visão holística, a abordagem indutiva e a investigação naturalística” (DENCKER, 2004, p. 35). Desta forma, este método atende ao estudo fracionado de determinados fenômenos para se apreender o todo.

Trata-se, pois de um Estudo Exploratório, uma vez que utiliza uma grande quantidade de dados de fontes secundárias, compreendendo além destas o estudo de caso selecionado e a observação informal (DENCKER, 2004, p. 128). Assim, estabeleceram-se os métodos desta pesquisa, que recorreu às técnicas de entrevista estruturada e análises qualitativas para 
analisar os valores e os usos do Jardim Botânico, pela comunidade que o cerca. Cabe ressaltar que, conforme corroboram Bartunek e Seo (2002) o método qualitativo é útil e necessário para identificar e explorar os significados dos fenômenos estudados e as interações que estabelecem, possibilitando estimular o desenvolvimento de novas compreensões sobre a variedade e a profundidade dos fenômenos sociais, ao passo que a análise quantitativa permite ratificar as análises, através da compilação dos dados apresentados.

Visando "imprimir" um quadro objetivo acerca dos valores e usos do Jardim Botânico, pela comunidade a pesquisa valeu-se do levantamento de dados secundários e primários in loco e das entrevistas estruturadas, de profundidade, aplicadas aos residentes das proximidades da área que abrange a Unidade de Conservação a ser implantada. Assim foram levantados dados secundários e primários, assim distribuídos:

Secundários: Dados de gabinete, apresentados pelo Instituto Brasileiro de Geografia e Estatística (IBGE); Instituto Nacional de Pesquisas Espaciais (INPE); Instituto Nacional de Meteorologia (INMET); $3^{\text {a }}$ Cia do Corpo de Bombeiros Militar de Ouro Preto-MG; Delegacia de Polícia Civil de Ouro Preto-MG; Prefeitura Municipal de Ouro Preto (PMOP), Instituto Estadual de Florestas (IEF), Associação de Moradores do Bairro São Cristóvão; bem como os levantamentos bibliográficos relativos ao tema estudado.

Primários: Foram realizadas 40 entrevistas, utilizando-se o método probabilístico aleatório ao acaso, para a escolha dos entrevistados. Assim, a escolha dos entrevistados utilizou-se do critério de disponibilidade, residência nos bairros e em alguns casos, a seleção de indivíduos que exerciam a função de liderança (formal ou informal), comércio, turismo, ou pesquisa na área do entorno, conforme apresentado no Quadro 1.

Foram realizadas ainda 5 visitas in loco na área onde, pretende-se implantar a UC, assim como em suas mediações, buscando o levantamento de informações, obtenção de dados específicos qualitativos e registro fotográfico da realidade encontrada. Os objetos de estudo basearam-se em relatos que apontam para a relação dos fatores socioeconômicos da população do entorno, uso e ocupação do solo, atributos culturais a fim de estabelecer os principais vetores de pressão para a área, relação da comunidade com o espaço bem como o levantamento de áreas de interesse turístico. 
Quadro 1: Entrevistados por entidade que representam

\begin{tabular}{|c|c|c|}
\hline $\begin{array}{c}\mathbf{N}^{\mathbf{0}} \\
\text { ENTREVIS- } \\
\text { TADOS }\end{array}$ & ENTIDADE & MEIO \\
\hline 4 & $\begin{array}{l}\text { Associação Comunitária de Moradores do Bairro } \\
\text { São Cristóvão }\end{array}$ & Entrevista em campo \\
\hline 3 & Instituto Estadual de Florestas - IEF & Entrevista em Gabinete \\
\hline 1 & $\begin{array}{l}\text { Secretaria Municipal de Turismo Indústria e } \\
\text { Comércio }\end{array}$ & Entrevista em Gabinete \\
\hline 1 & Secretaria Municipal de Desenvolvimento Social & Telefone \\
\hline 4 & Secretaria Municipal de Saúde & Telefone e no local de trabalho \\
\hline 1 & CAPS 1(Psicóloga) & Entrevista no local de trabalho \\
\hline 1 & Guarda Municipal & Telefone \\
\hline 2 & Policia Civil & Telefone \\
\hline 1 & Assistente Social (Fórum Municipal) & Telefone \\
\hline 2 & Secretaria Municipal de Meio Ambiente & Entrevista no local de trabalho \\
\hline 3 & $3^{\text {a }}$ CIA Corpo de Bombeiros Municipal & Telefone e e-mail \\
\hline 4 & ONG B1 - Núcleo Ouro Preto e Belo Horizonte & $\begin{array}{l}\text { E-mail; pessoalmente e por } \\
\text { telefone }\end{array}$ \\
\hline 10 & Moradores residentes nos bairros do entorno & Entrevista em campo \\
\hline 1 & SEMAE & Telefone \\
\hline 2 & Policia Ambiental & Telefone e e-mail \\
\hline
\end{tabular}

Nas entrevistas realizadas in loco, com os residentes no entorno, buscou-se compor um quadro com perspectivas mais humanizadas, com a percepção destes sobre os fatores condizentes com a pesquisa, seus temores e anseios. No decorrer da visita de levantamento de dados para pesquisa, os moradores serviram de guias, demonstrando fatores críticos e pontos fortes dos bairros do entorno bem como relatando as relações emocionais que estes possuíam com a área e o Jardim Botânico.

Após o compilamento dos dados obtidos em campo, nas pesquisas em gabinete e em registros documentais, foi realizada análise à luz das bibliografias consultadas e os resultados discutidos dentro da temática proposta para o estudo. Por fim, sugeriu-se algumas orientações para o manejo da nova UC.

O resultado do estudo foi dividido em quatro partes, assim distribuídas: Parte I - Aspectos socioeconômicos do entorno; Parte II - Vetores de pressão; Parte III - Usos da área; Parte IV Potencial para visitação pública e para o turismo. Os resultados dos estudos serão apresentados a seguir. 


\section{Aspectos Socioeconômicos do Entorno}

Esta parte do estudo pressupôs a identificação das principais características do entorno da UC a ser implantada como sugerido pela Lei Federal nº. 9.985, de 18/07/2000. Das informações obtidas destacam-se o fato da cidade de Ouro Preto, Patrimônio da Humanidade, situada na Serra do Espinhaço, inserida na Bacia do Rio São Francisco e sub-bacia do Rio Doce e ocupa uma área total de $1.246,53 \mathrm{Km}^{2}$, tendo 12 Distritos, além da sede, assim ocupa uma situação privilegiada, pois além dos atrativos arquitetônicos, datados do século XVIII, possuem um conjunto de outros atrativos naturais com potencial para se tornarem produtos turísticos (RET. PNMA, 2005).

De acordo com dados da Secretaria Municipal de Ouro Preto (SEMMA/OP), Ouro Preto está em meio a áreas de preservação ambiental e caracteriza-se como um mosaico de Unidades de Conservação, possuindo outras 10 Unidades de Conservação cadastradas (sendo seis em âmbito estadual e cinco municipais). O "Jardim Botânico", foco deste estudo, embora ainda não esteja incluído no mosaico, enquanto unidade de conservação constituída possui grande importância para o abastecimento hídrico da sede de Ouro Preto, além de possuir atributos arqueológicos, históricos e culturais que carecem de proteção legal.

Baseando-se em relatos orais dos moradores do entorno (transmitidos de geração em geração) e alguns poucos documentos (jornais e citações em artigos acadêmicos contendo registros da época) estima-se que o Jardim Botânico tenha sido estabelecido em 1825 por Ordenação Real, com a finalidade de cultivar plantas indígenas, exóticas como explica Sagawa (1996).

De acordo com o Relatório de Estudos Técnicos da Secretaria de Meio Ambiente de Ouro Preto (RET2010)

A busca pelo aprimoramento cientifico, em concomitância com o enriquecimento cultural em Vila Rica, desencadeia a iniciativa de implantação de um Jardim Botânico. A 13 de dezembro de 1798, o Conselho Ultramarino, órgão do governo português para administração das colônias, determina ao Governador das Minas Gerais que instale um Jardim Botânico em Vila Rica, tendo como modelo o Jardim Botânico implantado em Belém. Porém, apesar de interesse oficial, o Jardim Botânico de Ouro Preto parece não ter tido nos primeiros anos, o apoio financeiro que possibilitasse a implantação desejada.

As "Efemérides Mineiras", de José Pedro Xavier da Veiga (1897), menciona que somente em 2 de setembro de 1825 “inaugura-se o Jardim Botânico de Ouro Preto". Na sua implantação muito valeram a concepção e os conhecimentos de Joaquim Velloso de Miranda e José 
Mariano da Conceição Velloso, contemporâneo em Coimbra, ambos botânicos de expressão em suas épocas.

Relata-se no Jornal de Minas Gerais que a fundação oficial do Jardim Botânico tenha ocorrido por portaria em 02 de setembro de 1825. Além disso, tornou-se sede de uma escola agrícola com tecnologias modernas à época, na qual seriam cultivadas especiarias como o chá e seria produzido o bicho da seda. O que, em partes, pode ser conferido no registro do Jornal Minas Gerais (1907, p. 5):

O governo então mandava para o Jardim, sob tutela, os Africanos, que eram sequestrados aos contrabandistas, proibidos pela Lei abolicionista do tráfico de 1835. Eu conheci no Jardim mais de duzentos homens e mulheres salvos das garras da escravidão (gente vigorosa e boa), que traziam a terra como um brinco. [...]. O desembargador Quintiliano mandou ali plantar o chá, que rivalizou com o da China; amoreiras, cravo da Índia, canela, frutos, e outras especiarias exóticas de que se espalharam sementes. Criou-se o colmeal de abelhas (apis mellifera), e o bicho da seda (JORNAL MINAS GERAIS, 1907, p. 5, col. 3).

O Jardim Botânico adquiria assim a função educacional, somada as atividades comerciais provenientes das colheitas de espécies cultivadas no Jardim, pelos escravos. Durante os seus 40 anos de operação. Já Carvalho (1926), relata que o Jardim Botânico adquiriu caráter recreacional, para os habitantes da velha capital de Minas. Sobre suas finalidades, e funcionalidade, é possível mencionar ainda que:

O ensino da cultura e a propagação de plantas úteis indígenas e exóticas no jardim botânico fundado em Vila Rica (Ouro Preto), [...] obteve em sua direção homens capazes como os botânicos mineiros Veloso de Miranda e Fernando de Vasconcelos, o Jardim Botânico [...] e prestou reais serviços a Minas, introduzindo, principalmente na Província, a cultura do chá, da baunilha e do anil, assim como a criação de abelhas da Europa (JORNAL MINAS GERAIS, 1907, p. 5, col. 1).

As funções e importância do Jardim Botânico foram se alterando ao longo do tempo. Apesar disso, seu fechamento em 1864, denota uma incógnita até o momento, pois o que se percebe é que tal fato se deu, por motivos não muito claros, uma vez que não foram encontrados registros formais sobre tal fato. Para facilitar a visualização a Figura 1 revela a área de abrangência da Unidade de Conservação Jardim Botânico de Ouro Preto-MG. 


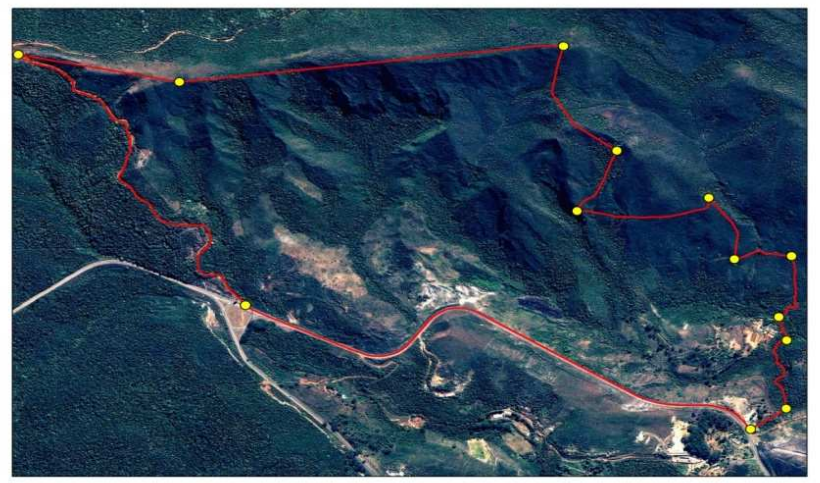

Figura 1: Área proposta para a criação da Unidade de Conservação do Jardim Botânico

Fonte: autores

De acordo com dados do censo 2010 a população do Município de Ouro Preto é de 70.227 habitantes, dos quais 40.5083 são residentes no distrito sede, denotando uma densidade demográfica de 56,41 hab./km² (IBGE, 2010). Em entrevista a responsáveis pelo Programa Social da Família PSF Renascer que atende a área do entorno, do Jardim Botânico, os mesmos informaram a existência de uma população estimada em 5.000 habitantes distribuída nos principais bairros limítrofes à área pretendida para abrangência da UC, a saber, bairros: São Francisco, Cabeças e São Cristóvão. No entanto, há uma tendência de aumento populacional, pois a alta dos preços de aluguel, nas imediações de bairros localizados próximos à Universidade (UFOP) e áreas centrais impulsiona a migração dos moradores permanentes destes bairros para bairros periféricos, tais como Cabeças e São Cristóvão, localizados no entorno da área do Jardim Botânico, ocasionando ocupação irregular e saturação da infraestrutura e consequiente pressão antrópica aos recursos naturais da área em especial na disponibilidade de água potável, cuja falta já é comum em períodos de alta temporada para o Turismo na cidade.

Quanto à área reservada a UC, há que se observar o vetor de pressão, uma vez que não há preparo adequado dos equipamentos e estruturas urbanas para o atendimento a demanda dos mesmos na cidade, sobrecarregando a infraestrutura existente, podendo causar conflitos de ordem socioambiental. Salienta-se aqui que o abastecimento de água de aproximadamente $60 \%$ da população da sede de Ouro Preto é proveniente da Estação de Tratamento de Água do Jardim Botânico, e que a água, no caso a sua ausência, é um dos fatores mais aparentes da saturação antrópica na cidade, o que torna a proteção de seus mananciais ainda elemento primordial para preservação. 


\section{Vetores de Pressão}

O impacto ambiental, de acordo com a Resolução $n^{\circ} 1$ de 1986, do Conselho Nacional do Meio Ambiente é caracterizado por qualquer alteração das propriedades físicas, químicas e biológicas do meio ambiente oriundas das atividades humanas, que possam, direta ou indiretamente, afetar: a saúde, a segurança e o bem estar da população; as atividades sociais e econômicas; a biota; as condições estéticas e sanitárias do meio ambiente; a qualidade dos recursos ambientais (CONAMA, 1986). O termo perturbação ambiental remete a ideia de grandes desastres naturais. Entretanto, não são apenas os grandes desastres, os modificadores da paisagem, alterações de menor porte podem ser responsáveis por grandes impactos ao meio ambiente. O que determina a dimensão do impacto é sua relação sobre a área analisada. Por isso, mesmo as pequenas áreas podem ser impactadas pela presença antrópica. Logo, estudos que assegurem conhecimentos sobre dinâmica de um ecossistema e seus agentes modificadores são fundamentais para que haja a conservação de tais locais.

O impacto antrópico em áreas de preservação pode ser tanto positivo, quanto negativo, a depender da situação. Entre os impactos positivos do uso das unidades de conservação é possível citar a difusão de informação ambiental por meio de programas de educação ambiental que auxilia na conservação destes ambientes por meio de uma sensibilização ambiental da comunidade residente e dos visitantes. Já os impactos negativos podem ser destacados como: o corte prematuro e desordenados de plantas nativas, o que favorece a disseminação de espécies exóticas, desmatamento ilegal e ações depredatórias de diversas formas, atingindo fauna, flora e edificações existentes.

As fotos da Figura 2 apontam para os danos causados pelo tempo e pela ação de vandalismo. Comparando-as é possível perceber a destruição de parte das ruínas do portão principal do antigo Jardim Botânico. Destruição estas atribuída ao tempo, falta de cuidado e ações de vandalismo.

Além do processo depredatório provocado pelo tempo, parte das ruínas do antigo Jardim Botânico está sendo alvo de vandalismo. Foram registradas, quebra de estrutura e pichações nas paredes de todas as ruínas que afetou a beleza cênica do lugar. 


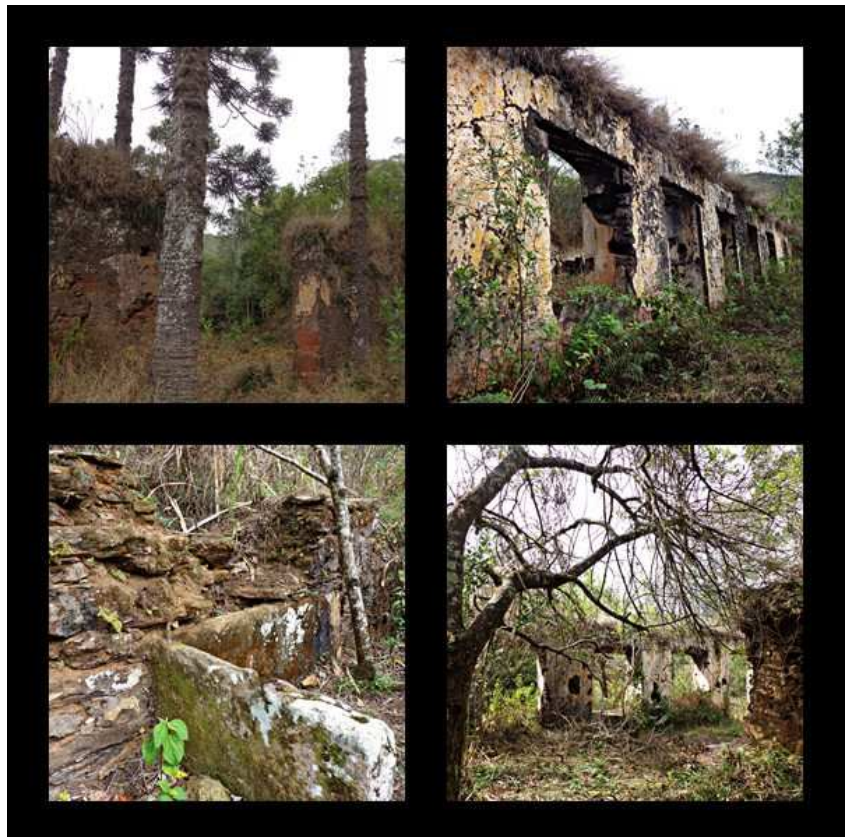

Figura 2: Ruínas Jardim Botânico depredadas por vandalismo, 2014

Fonte: autores

Entrevistas realizadas junto a representantes da Secretaria Municipal de Meio Ambiente indicaram que da década de 60 até o ano de 2006 houve um aumento gradativo das áreas ocupadas. Em 1966 do total da área do Jardim Botânico, 2.6 hectares representavam áreas ocupadas, que em 1986 atingiu um valor de 5,8 e em 2006 este valor subiu para 20,5 hectares. As edificações avaliadas em 1986 totalizavam 22 e este valor aumentou para o dobro, 44 edificações, SEMMA (2015). Estes fatos demonstram o abando em que a área se encontrava.

Ainda de acordo com a Secretaria Municipal de Meio Ambiente SEMMA (2015), diante destas iniciativas, em 2012, o quantitativo de invasões fundiárias na área do Jardim Botânico retrocedeu. No entanto, em 2014 novas invasões foram relatadas, estando essas em disputa judicial em virtude de denúncias e notificações realizadas por órgãos responsáveis. Entretanto, há ainda expansão urbana e ocupação desordenada recente, próximo a mundéus, sarilhos, outros resquícios arqueológicos e ao limite da área proposta para a criação da Unidade de Conservação Jardim Botânico.

A precariedade da infraestrutura urbana nesta área pode ser observada pela falta de coletores de esgoto, de coleta de lixo são agravantes no quadro de poluição hídrica e incidência de incêndios na área, implica ainda redução na área de amortecimento da Unidade de Conservação e em situação propícia para o aumento da marginalidade e depredação das ruínas arqueológicas. Soma-se a isto a falta de planejamento adequado para essa expansão. Desta 
forma, tais ocupações tornam-se fator relevante enquanto vetor de pressão, já que são altos os riscos geológicos que a área apresenta com processos irregulares agregados a fatores como o excesso de precipitação, propriedades geológicas e geomorfológicas acarretam no aumento do risco de escorregamentos e processos erosivos, principalmente no Bairro São Cristóvão, conforme demonstrado na Figura 3.

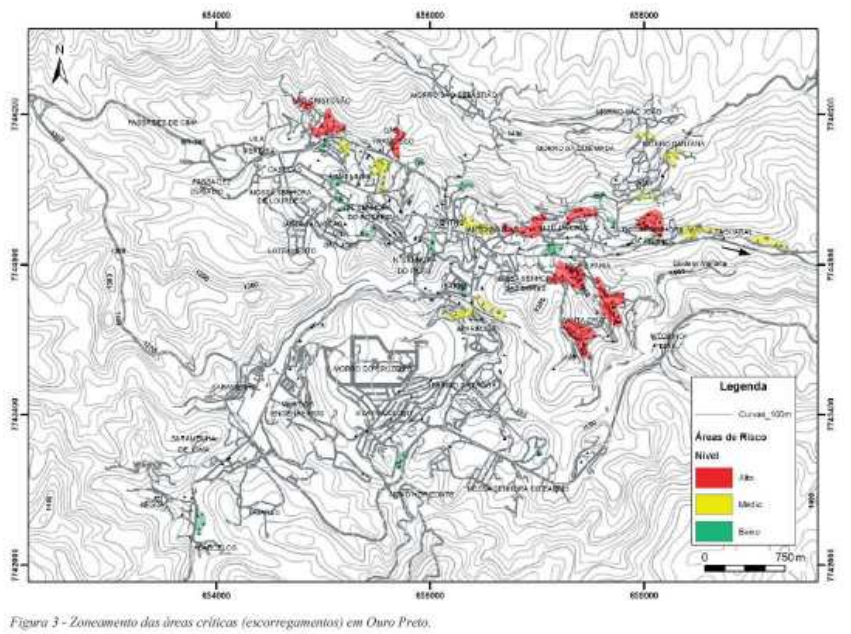

Figura 3: Proposição de procedimentos preventivo de riscos geológicos em Ouro Preto, com base em histórico de ocorrências e sua correlação com a pluviosidade

Fonte: (SOUZA. M. L. 1996).

Ao longo das últimas décadas tem sido observado um aumento significativo na movimentação e escorregamento de terras, nesta área, ratificando esta região, como uma das mais críticas, para o uso e ocupação, ratificando o mapeamento Proposição realizado por SOUZA (1996). Além disso, na região citada é comum à ocorrência de incêndios, em época de seca prolongada, muitas vezes de origem antrópica, sejam estes criminosos ou acidentais, decorrentes de práticas irregulares de queimada de lixo no entorno, de vegetação para abertura de pastos ou para a agricultura.

Frisa-se que a incidência de incêndios em área verdes localizadas em Ouro Preto teve um aumento de, aproximadamente 200\%, entre 2009 e 2014, conforme relatório da $3^{\text {a }}$ CIA de Bombeiros de Ouro Preto-MG (RFI. $3^{\text {a }}$ CIA.,2014). Este dado alarmante demonstra a falta de ações preservacionistas e de mitigação de impacto na localidade. Ressalta-se que além dos prejuízos a fauna e flora, os incêndios aumentam a poluição do ar e representam risco à saúde humana. Nesse sentido, a criação de uma UC seria benéfica aos moradores da região, uma vez que estabeleceria um limite, e de certa forma a fiscalização, em relação à ocupação desordenada. 
Apesar disso, parte das entrevistas sinaliza para a resistência da comunidade, quanto a um processo de desapropriação decorrente da criação de uma Unidade de Conservação de Proteção Integral, compatível à Parque Natural Arqueológico ou Cultural. No entender deles, as construções já estão consolidadas, não cabendo, portanto, desapropriação. Além disso, muitos temem a perda do espaço de uso comunitário que é o Jardim Botânico. Àqueles que são favoráveis, anseiam pela criação de algo que proporcione melhorias ao bairro como: saneamento, acessibilidade, geração de empregos e educação, e consiga conciliar a proteção da área com as necessidades dos que habitam o seu entorno.

Diante da documentação analisada, até o momento, é possível afirmar que caso não haja proteção e medidas mitigatórias, a diminuição do abastecimento hídrico será reduzido, favorecendo a escassez de água em época de estiagem e a erosão em épocas chuvosas. Portanto, urge estabelecer programas de informação, reflexão e conscientização da população local, antes mesmo que o processo de criação da UC possa ser concluído.

\section{Usos da Terra}

Dentre os principais usos atuais da área do Jardim Botânico destacam-se a visitação turística, realizada de forma espontânea, pelo alto da serra que liga a saída de Ouro Preto ao bairro São Cristóvão, geralmente sem o acompanhamento de profissionais do setor publico ou privado e por divulgação informal; a produção de mudas de espécies arbóreas nativas do Viveiro Municipal para a recuperação de áreas degradadas, que encontra-se atualmente sob gestão da Secretária Municipal de Meio Ambiente; e a Estação de Tratamento de Água gerenciada pelo SEMAE, responsável pelo abastecimento hídrico de mais de $60 \%$ da população do distrito sede de Ouro Preto.

Verifica-se ainda a criação ilegal de equinos, a extração de espécies exóticas e nativas pela população do entorno para usos fitoterápicos e para comercialização. E, lamentavelmente, soma-se a este quadro o descarte de lixo e efluentes sanitários das propriedades localizadas nas áreas limítrofes, pelos moradores e residências que não possuem saneamento básico. Além disto, os indicadores do sistema de esgotamento sanitário do município de Ouro Preto não são satisfatórios, visto que hoje o sistema tem somente rede coletora de efluentes domésticos em uma parte da cidade (região central e do bairro Itacolomi). No restante do município (principalmente os morros e área periférica), os efluentes são lançados em galerias 
de águas pluviais, diretamente nos corpos hídricos, na drenagem natural ou são utilizados sistemas de tratamento individual em desconformidade com os padrões mínimos de construção como é o caso das fossas negras como constado no Plano Municipal de Saneamento Básico de Ouro Preto, versão Preliminar. (2011).

No percurso das trilhas, é possível visualizar ainda vestígios de extração de rochas, para pesquisa, segundo relatos, embora sem nenhum tipo de regularização. Presença de "botafora", onde são depositados entulhos e lixo. Inclusive rejeito oriundo de descarte de construção civil. São comuns ainda aberturas de vias secundárias para o trânsito de pedestres, e incêndios, muito criminosos, decorrentes da limpeza de lotes para construção, da abertura de vias para o pastoreio e pela incineração de lixo nos pontos onde a coleta não atende no entorno da área ou mesmo por piromaníacos. Logo, tendo em vista as informações expostas, nota-se a necessidade de melhor ordenamento e fiscalização das atividades ali praticadas a fim de evitar a degradação do espaço.

\section{Potencial para Visitação Pública e para o Turismo}

O turismo é um dos mais relevantes setores da atividade econômica no Brasil, sendo tomado como uma alternativa na geração de renda e emprego, já é capaz de oferecer menor impacto ao meio ambiente, comparado às outras atividades dinâmicas da economia tais como a mineração e a agricultura. Porém, Swarbrooke (2000) corrobora que, quando se visa à sustentabilidade da atividade, o turismo não deve estar embasado apenas na proteção da natureza, mas também à viabilidade econômica em longo prazo e a justiça social.

A atividade do turismo acontece durante o deslocamento e a permanência do indivíduo fora da sua residência (OMT, 2003). Os negócios turísticos são os realizados nos equipamentos, ou durante a prestação de serviços que os turistas utilizam na preparação e na execução da sua atividade Barreto (2003). Sendo, portanto, um ato praticado por pessoas que realizam uma atividade específica de lazer, fora das suas respectivas cidades e que utilizam equipamentos e serviços cuja prestação constitui um negócio, para atingir seus objetivos.

No que tange as Unidades de Conservação, a visitação pode trazer como benefícios o auxílio financeiro para a manutenção das áreas e outros financiamentos que auxiliem na conservação destas áreas. Nesse sentido, é licita a afirmação de Lindberg (1999), segundo o qual a promoção de um planejamento contendo diretrizes e diagnóstico do ecoturismo tende a ser um 
fator indispensável para a diminuição dos custos e maximização dos benefícios para todos os segmentos representados e envolvidos no turismo de uma área natural. Portanto deve ser uma iniciativa "acolhida" e representativa de todos os segmentos envolvidos, na medida em que seus anseios confluírem na direção da conservação, da educação ambiental e da melhoria da administração dos recursos para o atendimento dos turistas (CHAVES, 2012, P. 77).

A instalação da UC, com visitação turística aos atrativos, ampliaria o leque de atrativos naturais da cidade de Ouro Preto-MG. Portanto, a título de possibilitar vantagens aos demais segmentos relacionados ao turismo local, isto deveria ser envolvido na pauta das discussões do planejamento turístico de Ouro Preto, a estruturação de um plano de infraestrutura, marketing/propaganda e gestão dos atrativos com potencial ecoturístico (CHAVES, 2012). No entanto, são questões que ultrapassam a demanda desta pesquisa e que não serão discutidas aqui, por inadequação ao tema proposto. Ressalta-se que, a promoção do Jardim Botânico como UC e atrativo corrobora o potencial turístico da cidade e comprova que, em Ouro Preto (e seus distritos), existe um patrimônio natural exuberante, com exemplares de rara beleza, tão merecedores de visitação e preservação quanto o patrimônio edificado.

A destinação turística não é um produto único e homogêneo, mas sim um composto de muitos produtos compostos por atrativos diversificados e separados cabendo ao turista a escolha dos mesmos a e a escolha pela melhor forma de elaboração de seu roteiro. Neste contexto, cumpre informar que Ouro Preto é uma cidade colonial tricentenária e que, além de seus atrativos edificados e internacionalmente reconhecidos, possui um rico e variado ecossistema em seu entorno, com cachoeiras, trilhas seculares e uma enorme área de mata nativa, sendo algumas protegidas pela criação de Parques Estaduais e Municipais para os quais o turismo poderia ser direcionado. Uma decisão neste sentido seria responsável pela diminuição dos efeitos da sobrecarga do Centro histórico, distribuindo melhor os benefícios provenientes de todo o trade turístico.

No caso do Jardim botânico, a contribuição do turismo para a geração de riquezas e melhoria do bem estar da comunidade anfitriã pode ser sentida de múltiplas maneiras, na geração de emprego; distribuição e circulação de renda; transferência de recursos de regiões mais ricas para regiões menos favorecidas, naquilo que designa na economia, como efeito convergência, nos investimentos e inovações tecnológicas, no desenvolvimento de infraestruturas coletivas, na preservação do ambiente e recuperação do patrimônio histórico e cultural, nas oportunidades de desenvolvimento e nas necessidades dos viajantes (OMT, 2003). Esses 
efeitos interagem em diversos domínios da sociedade e, de maneira geral, envolvem de forma sinérgica os ambientes: cultural, ecológico, econômico, político e social.

O turismo baseado na comunidade não requer, necessariamente, hotéis luxuosos, como instituições propícias ao seu desenvolvimento. Pois, a exigência inicial é de ambientes capazes de oferecer acolhida, alimentação e segurança (CAMARGO, 2004). Por isso, o turismo pode recorrer a pousadas, restaurantes, guias turísticos, operadores turísticos responsáveis e demais interessados que estejam dispostos a utilizar os bens e serviços locais, de forma sustentável, para a tal fim.

Além da realização usual de visitação, a promoção de um atrativo turístico pode envolver atividades como mostras culturais, circuitos, roteiros turísticos, etc. Por isso, usualmente, para iniciar este tipo de atividade nos bairros do entorno ao Jardim Botânico é necessário apenas a existência de certo volume de fluxo turístico e uma infraestrutura básica e consequentemente o planejamento turístico, propiciado, em sua maioria, por instituições públicas, no caso de Ouro Preto, pela Secretaria de Turismo, Indústria e Comércio (SETIC).

No levantamento de fontes primárias e secundárias, realizado sobre o Jardim Botânico de Ouro Preto-MG, foi possível constatar que a área analisada para implantação da UC já existe um modesto fluxo de visitação aos seus atributos culturais, tais como as ruínas das minas, e naturais, como as trilhas e cachoeiras, que compreendem ainda formações rochosas, fragmentos de mata nativa, mirantes com vista privilegiada das Unidades de Conservação que o circundam e da cidade de Ouro Preto. Constatou-se ainda, em visita às imediações do Jardim Botânico, que a comunidade do entorno começa a se organizar visando ao benefício de oportunidades que o turismo pode proporcionar. Assim, estão sendo organizadas caminhadas guiadas (formal e informalmente), feiras de artesanato, oficinas de pintura e fotografia, visitação as ruínas da mineração já podem ser observadas, gerando renda para a comunidade e valorizando cultura local. Salienta-se ainda a existência no local, e nas proximidades, de tentativas de implementação de atividades voltadas ao turismo como minas abertas à visitação, tal qual a Mina Du Veloso e aquedutos do Sec. XVIII.

Além disso, os bairros já contam com uma estrutura de hospedagem com hotéis de pequeno porte e pousadas, com opções de restaurantes cujos pratos são preparados de acordo com a gastronomia local, bem como o elemento facilitador que é o próprio terminal de receptivo turístico nas imediações. 
Nas entrevistas a moradores e representantes da instituição Associação Comunitária de Moradores do Bairro São Cristóvão foram relatadas a existência de visitas periódicas de grupos de estudantes, ao Jardim Botânico. Nas visitas in loco, realizadas em novembro de 2014, também foi perceptível a presença de ciclistas e transeuntes, o que imprime diferentes usos do lugar. Cabe ressaltar que, o turismo assumindo os princípios do ecoturismo, tem papel destacado na questão de conservação da natureza, sendo um dos negócios ambientalmente corretos mais indicados para áreas protegidas, tanto em Unidades de Conservação quanto em áreas protegidas por outros mecanismos legais ou não, como tradições locais ou estratégias de mercado, conforme corrobora Dale (2005). É ainda uma forma de dividir experiências que levam as pessoas a compreender e cooperar com a conservação dos recursos naturais.

Para tanto, no que diz respeito ao uso turístico o Jardim Botânico conta, entre seus atrativos naturais, com a presença de nascentes, cachoeiras e lagoas, sendo a Lagoa Azul (embora, atualmente, bastante assoreada) o principal atrativo natural buscado pelos visitantes. Próximo à Lagoa Azul, existe ainda ruínas e vestígios do que viria a ser um reservatório de água e que era utilizado para abastecimento de água dos mundéus. Soma-se a isto a beleza cênica das formações geológicas, que também tornam-se parte da atratividade, como pode ser verificado na Figura 4.

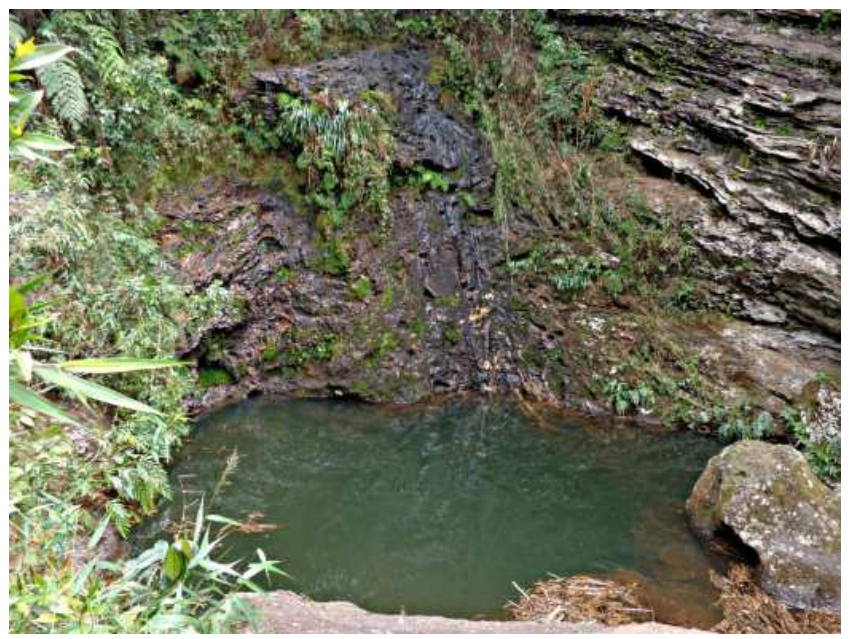

Figura 4: Lagoa azul do Jardim Botânico

Fonte: autores

Dentre as atividades turísticas e de visitação mais praticadas no Jardim Botânico, podem ser citadas: o ecoturismo, o turismo cultural e o turismo de aventura. No entanto, sem o planejamento adequado e sem a formalização da UC, as visitações ocorrem de maneira informal e o visitante pode ser comparado à visita de um amigo em casa, que é deixado sozinho, após abrirmos as portas para que ele entre e saia, como pontua Hipki e Lomis Junior 
(1981). Por estas e outras razões, o estudo vai conduzindo à percepção de benefícios na implementação da UC, uma vez que poderão ser propiciados e formalizados os processos de turistificação do local, da maneira mais adequada possível.

Os autores Lindiberg e Hawkins (1999) colocam que a premissa do ecoturismo é promover a atividade turística sem afetar ou destruir o frágil ecossistema onde o mesmo é praticado. Este segmento de turismo é considerado, portanto, uma viagem de cunho responsável a áreas naturais, visando à preservação do meio ambiente, a promoção do bem estar da comunidade local e a satisfação do turismo.

Sob a égide do ecoturismo, vem se praticando uma inadequada interpretação do conceito. Muitas localidades são divulgadas devido ao potencial para tal fim, embora a atividade praticada não seja caracterizada como tal como coloca. Assim, as unidades de conservação são destinos que se destacam por tal potencial, expostas a um intenso fluxo de turistas e visitantes locais que veem no mesmo uma alternativa para a contemplação da natureza o estudo e o lazer. Entretanto, o despreparo para receber um grande contingente de pessoas se expressa na precariedade estrutural das mesmas e na ausência de um planejamento técnico-científico em nível socioambiental, econômico e cultural. Tal como na ausência de recursos administrativos, físicos e financeiros suficientes para atender eficazmente as demandas existentes.

De acordo com Beni (2001), o objetivo, a duração da viagem e a distância viajada caracterizaramse como os três principais elementos para a construção de diferentes definições de turistas. Nesse sentido a Organização Mundial do Turismo (OMT, 2003), caracterizam esses consumidores em turistas, excursionistas e visitantes. Tratando dos aspectos físicos do Jardim Botânico, os visitantes entrevistados, em sua maioria excursionistas, encontrados no decorrer da visita à área, informaram que entre as suas aspirações ao realizar visitação nesta localidade estão: encontrar a natureza preservada (e não estruturas de grande porte que impactem o local). Portanto, deve-se tomar certo cuidado acerca da infraestrutura a ser implantada, devendo estas ser mínimas e adaptadas ao ambiente para que fique à mostra aos visitantes, aquilo que eles procuram, que são amostras da natureza primitiva pouco impactada.

A imagem de uma determinada área, enquanto Unidade de Conservação traz implícita a valoração da mesma quanto as suas funções de preservação ambiental, adequada à modalidade que lhe foi atribuída. Chamando à atenção de seus visitantes, residentes e gestores para a sua função de manutenção de ambientes naturais de relevante interesse ambiental, 
cultural, cênico para o viés da preservação, visando o uso sustentável, tal como se pode vislumbrar, na paisagem panorâmica oferecida em vários pontos do Jardim Botânico, como pode ser comprovado na Figura 5.

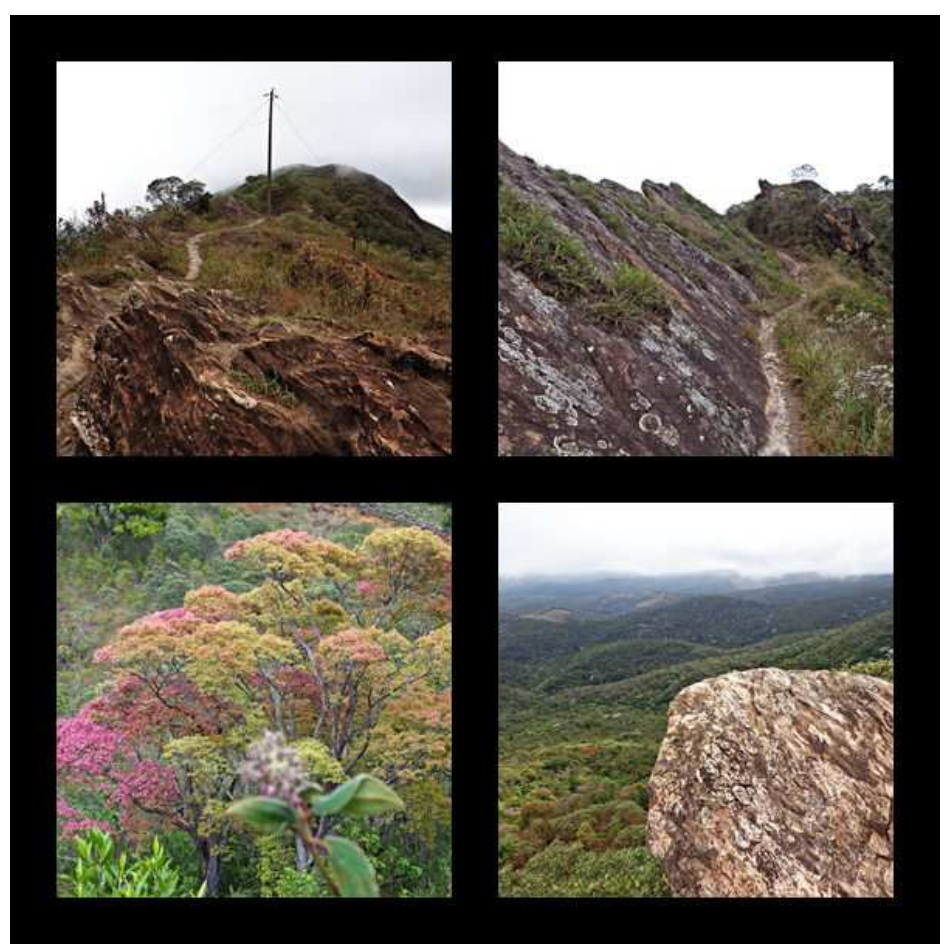

Figura 5: Vista da trilha da serra do Jardim Botânico (vista da APA das Andorinhas)

Fonte: autores

Assim o Turismo Ecológico, destaca-se como instrumento de sensibilização, que é a primeira etapa que constitui a conscientização, no esforço de promover a preservação ambienta na nova UC. Nesse sentido a transformação da área em UC, propiciaria ainda o aumento do número de visitantes e na qualidade da visitação que ali pode se desenvolver, visto que a criação da UC envolve em aumento de investimento em estrutura física e qualificação profissional. Por consequência, a criação da UC e o desenvolvimento da atividade turística tornam-se vetores de promoção e preservação desta área.

É possível observar praticantes de diversas modalidades de turismo de aventura na área do Jardim Botânico, ciclismo, trekking, rapel e escalada para iniciantes fazem parte da gama de opções que o espaço oferece. No entanto, embora tais atividades estejam cada vez mais freqüentes na área, dadas as condições geológicas da região, recomenda-se que as categorias de visitação preferenciais para a UC sejam o turismo ecológico, educativo e recreacional, 
sujeitas às normas pré-estabelecidas e fiscalizadas por órgão responsável a fim de prevenir e mitigar ações predatórias ou que ofereçam dano à integridade física da UC.

Tendo em vista as características físicas, sociais e econômicas apresentadas no estudo, recomenda-se a realização das seguintes ações para o manejo da UC:

Quadro 2: Recomendações para implantação de infraestrutura na UC.

\begin{tabular}{|l|l|}
\hline $\mathbf{N}^{\mathbf{0}}$ & \multicolumn{1}{|c|}{ RECOMENDAÇÕES: } \\
\hline $\mathbf{1 .}$ & Recomposição e recuperação ecossistêmica; \\
\hline $\mathbf{2 .}$ & $\begin{array}{l}\text { Levantamento, estudo e recuperação das ruínas visando à adequação das mesmas para a criação } \\
\text { de um centro de referência histórico objetivando a recuperação da memória cultural e das raizes } \\
\text { locais; }\end{array}$ \\
\hline $\mathbf{3 .}$ & $\begin{array}{l}\text { Considerando a necessidade de possíveis construções, que sejam escolhidos locais abandonados, } \\
\text { ao invés de áreas com vegetação nativa para que haja impacto positivo sobre o meio ambiente; }\end{array}$ \\
\hline 4. & $\begin{array}{l}\text { É essencial a consulta à comunidade local acerca da categoria de manejo a ser implantada assim } \\
\text { como a participação da mesma em todas as etapas do processo de planejamento gestão; }\end{array}$ \\
\hline $\mathbf{5 .}$ & $\begin{array}{l}\text { É importante a seleção de local que não necessite de nova infraestrutura de transporte e acesso } \\
\text { para centro de convivência e incentivo ao uso de transportes coletivos a fim de evitar poluição, } \\
\text { ruídos e congestionamentos considerando ainda a preservação dos aspectos estéticos locais; }\end{array}$ \\
\hline 6. & $\begin{array}{l}\text { Estabelecimento de programas educativos, de marketing orientado, reciclagem, assim como de } \\
\text { prevenção e combate a incêndios; }\end{array}$ \\
\hline 7. & $\begin{array}{l}\text { Construção de centro administrativo e/ou receptivo onde não haja escassez de recursos como } \\
\text { água e energia elétrica; }\end{array}$ \\
\hline 8. & $\begin{array}{l}\text { Opção por projeto arquitetônico que utilize de materiais de construção locais, em estilo } \\
\text { tradicional da região, sempre que possível; Levantamento de dados de visitação e monitoramento } \\
\text { de impacto constantes; }\end{array}$ \\
\hline 9. & $\begin{array}{l}\text { Estudo que viabilize a visitação das áreas naturais sem exceder a capacidade de carga física, } \\
\text { ambiental, econômica, sociocultural, estrutural e perceptiva do local e do entorno, evitando assim } \\
\text { danos socioambientais; }\end{array}$ \\
\hline $\mathbf{1 0 .}$ & Contratação de empreiteiras e mão de obra local para execução de serviços. \\
\hline
\end{tabular}

Fonte: Contribuição dos autores frente a realidade observada e à luz do proposto como adequado para UC pela bibliografia consultada.

Ressalta-se que o estudo ocupou-se em identificar potencial turístico e ambiental, no entanto, há ainda e a necessidade de adequar os usos atuais das terras ocupadas no interior da área de interesse para criação da UC, visando à recuperação da área degradada, das ruínas e da mata ciliar, assegurando a qualidade da área de recarga hídrica.

Com relação ao turismo, sugere-se delimitar o número de visitantes em áreas mais sensíveis à presença os mesmos, tais como nos topos das serras, cachoeiras e áreas onde a vegetação encontra-se em estado de recuperação, para isso, é relevante a promoção de um Estudo de Capacidade de Carga. Deve-se atentar à necessidade de se estabelecer uma capacidade de carga viável do ponto de vista econômico, de infraestrutura e perceptiva. Tendo em vista que a atividade de visitação não deve afetar a comunidade local em questões como o aumento nos preços de 
moradia e alimentação. O aumento exagerado de turistas pode sobrecarregar a infraestrutura local, que já apresenta certa precariedade e pode alterar a qualidade dos atrativos culturais do Jardim Botânico, descaracterizando suas paisagens naturais e as suas ruínas arqueológicas.

É importante focar nos recursos humanos utilizados. O ideal é a utilização de mão de obra local, e no treinamento e capacitação dos mesmos, gerando renda para a região. A "indústria do turismo" é conhecida pela baixa remuneração, alta rotatividade de mão de obra, sazonalidade, dificuldade de ascensão profissional e discriminação dos seus empregados Lage, B. H. G. e Milone, P. C. (1998). Esse quadro pode e deve ser evitado por meio de treinamento, capacitação, incentivo. Cabe ressaltar que a empregabilidade no setor do turismo também oferece vantagens tais como oportunidade de emprego para jovens e aumento no número de empregos ofertados. Além disso, um setor seguro e oferece poucos riscos de acidentes decorrentes da atividade, oferecendo ainda a oportunidade de convivência com pessoas de diferentes localidades/nacionalidades, o que pode gerar uma ampliação de percepções culturais.

Quanto aos atrativos históricos que compõem esta área, deve-se ressaltar que os próprios vestígios da atividade de mineração, comuns à região da Estrada Real, integram o Turismo Histórico Cultural, que é feito do conjunto histórico e das ações humanas no espaço. De tal forma que, no Jardim Botânico, estes vestígios ainda são visíveis mesmo depois vários séculos, desde a sua desativação. Os vestígios encontrados no Jardim Botânico são exemplares raros, porque, dificilmente, estes vestígios encontram-se isolados. Em sua maioria são: barragens, canais de veiculação hídrica, áreas de desmonte, sarilhos, mundéus, galerias, montes de sedimento revirado, desvios dentre outros (Figura 6).

Nesse sentido, merece ser lembrado que no Jardim Botânico e em seu entorno, ainda é possível encontrar 3 aquedutos, de fácil visibilidade e ainda mundéus, cujos exemplares em bom estado de conservação são raros. Porém, os mesmos ainda podem ser visualizados na parte mais alta de ocupação do Morro São Cristóvão. Há ainda inúmeras galerias subterrâneas que objetivavam acompanhar os veios mineralizados, bem como sarilhos, que são aberturas, na terra, responsáveis pela ventilação das minas, estes mais facilmente encontrados na região de Ouro Preto, embora muitos já se encontrem soterrados ou cobertos por lixo. 


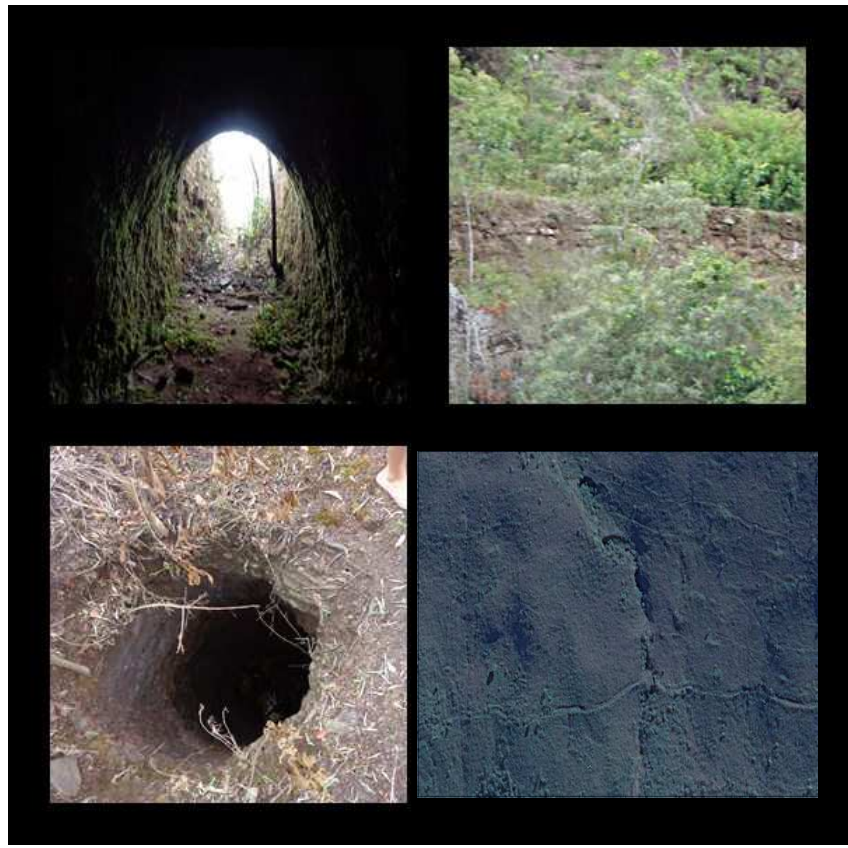

Figura 6: Minas, Mundéus, sarilhos e aquedutos

Fonte: autores

Ressalta-se a esse respeito que as galerias de mineração cortam a Serra de Ouro Preto, trazendo consigo a herança cultural e os riscos geológicos provenientes da sua existência. Um canal, quase sempre estabelece a ligação entre uma barragem ou represa de captação, e uma área de extração em outra. As áreas de extração podem conter galerias, muros de arrimo, mundéus, montes de rejeito. Disto decorre a necessidade estudar cada vestígio como parte de uma realidade mais ampla e complexa a fim de não impacta-los ou de atrapalhar a reconstrução de sua memória que será foco principal do turismo cultural e educacional na região.

O turismo cultural na área do entorno à UC pode apropriar-se de manifestações de grupos culturais como o Grupo de Congado Nossa Senhora do Rosário e São Cristóvão; Grupo das Pastorinhas de São Cristóvão; Escola de Samba Acadêmicos de São Cristóvão e Bloco do Mato; artesanato como a Renda Marafunda; bordado, tricô, crochê e pinturas para o desenvolvimento da atividade. Assim a concepção da UC Jardim Botânico de Ouro Preto agrega elementos de diversas fontes, dando ênfase ao conjunto. De um lado a ideia dos parques arqueológicos e ambientais clássicos, de outro a preservação de um sítio histórico aberto à visitação pública, incentivando e fortalecendo as raízes culturais da comunidade local. 


\section{Considerações Finais}

Tendo em vista os objetivos da pesquisa, a saber, analisar se o Jardim Botânico de Ouro Preto se enquadra nos quesitos necessários para se tornar uma Unidade de Conservação conforme exporto pelo SNUC; averiguar a viabilidade da implementação da atividade turística na área; analisar qual a percepção destes fatos, pelas comunidades do entorno da nova UC. A pesquisa apontou triplo mérito para a área do Jardim Botânico: 1) O caráter ambiental que remete à necessidade de proteção de fragmentos de áreas verdes, nativas e exóticas bem como a necessidade de resguardar importante manancial hídrico da região. 2) A importância no fortalecimento do corredor ecológico formado pelo mosaico de Unidades de Conservação de Ouro Preto; 3) A relevância da área para o desenvolvimento da atividade turística, em especial para as atividades de ecoturístico e turismo histórico-cultural.

Quanto à percepção dos moradores, no decorrer da pesquisa foram constatadas inúmeras carências nas imediações do Jardim Botânico e que precisam ser priorizadas caso venha a ocorrer a implementação da UC, com intuito de desenvolvimento turístico tais como: carência de infraestrutura, alto risco geológico em algumas localidades.

Foram observadas ainda pressões antrópicas que podem comprometer a qualidade da área como invasões fundiárias e questões de ordem sociocultural, tais como a marginalidade e o vandalismo, entre outros.

Ressaltou-se que a criação da UC não deve tolher os direitos humanos da comunidade residente, nem privá-la de recursos essenciais para a sua sobrevivência. Foram registrados como pontos fortes, observados: a presença de visitantes e o potencial turístico dos atrativos de grande valor histórico, arqueológico, cultural e natural, bem como a proximidade a pequenos centros comerciais, a postos de atendimento à saúde, tal qual a facilidade de acesso à Rodovia dos Inconfidentes, há ainda uma associação de bairro e tentativas de organização comunitária visando ao atendimento da demanda local existente para o turismo.

Salientou-se que comunidade precisa ser devidamente preparada e capacitada para a recepção do turismo, para que a mesma não seja prejudicada e haja uma minimização dos impactos negativos na UC decorrente da atividade.

Sugere-se a criação da UC, visto que a área atende os critérios exigidos pelo SNUC, entretanto, é imprescindível que estes processos ocorram de forma democrática, através de instrumentos adequados à participação e conscientização da população e também dos 
dirigentes das políticas públicas locais, para que a Unidade de Conservação Jardim Botânico de Ouro Preto-MG seja realmente um benefício relacionados a este Patrimônio Histórico Cultural. Porém, cabe ainda a realização estudos mais aprofundados, a fim de mensurar os impactos provenientes da criação da UC bem como na comunidade que a circunda.

\section{Referências}

BARRETTO, Margarita. O imprescindível aporte das ciências sociais para o planejamento e a compreensão do turismo. In: Horizontes Antropológicos, vol. 9, nº. 20, p. 15-29, 2003.

BARONI, Margareth. Ambiguidades e deficiências do conceito de desenvolvimento sustentável. Revista Administração de Empresas, São Paulo, 32 (2): p. 14-24, 1992.

BARTUNEK, J. M.; SEO, M. Qualitative research can add new meanings to quantitative research. Journal of Organizational Behavior, v. 23, n.2, 2002.

BENJAMIN, Antonio Herman de Vasconcelos. Meio ambiente e Constituição: uma primeira abordagem. In: BENJAMIN, Antonio Herrnan (Ed.). 10 anos da Eco 92: o direito e o desenvolvimento sustentável. São Paulo: IMESP, 2002.

BENI, Mário Carlos. Análise estrutural do turismo. São Paulo: SENAC, 2001.

BRASIL. CONSTITUIÇÃO FEDERAL DE 1988. Disponível em: <http://www.planalto.gov.br/ccivil_03/constituicao/constitui\%C3\%A7ao.htm>. Acesso em 22 abr. 2014.

BRASIL. DECRETO $\mathrm{n}^{\circ} 4.340$, de 22 de agosto de 2002. Regulamenta artigos da Lei $n^{\circ} 9.985$, de 18 de julho de 2000, que dispõe sobre o Sistema Nacional de Unidades de Conservação da Natureza SNUC. Disponível em: < http://www.planalto.gov.br/ccivil_03/decreto/2002/d4340.htm>. Acesso em mar. 2014.

BRASIL. Lei ${ }^{\circ} 6.938$ de 31 de agosto de 1981. Leis da República Federativa do Brasil, Brasília, DF, 1981. Disponível em: < http://www.planalto.gov.br/ccivil_03/Leis/L6938.htm.> Acesso em 20 jan. 2014.

BRASIL. Lei no 9985 de 18 de julho de 2000. Leis da República Federativa do Brasil, Brasília, DF, 2000. Disponível em: <http://www.planalto.gov.br/ccivil_03/LEIS/L9985.htm〉. Acesso em 10 fev. 2014.

BRASIL. Lei no 9605 de 12 de fevereiro de 1998. Leis da República Federativa do Brasil, Brasília, DF, 1998. Disponível em: <http://www.planalto.gov.br/ccivil_03/LEIS/L9605.htm>. Acesso em 10 fev. 2014.

CAMARGO, Luis Otávio de Lima. Os domínios da hospitalidade. In: DENCKER, Ada de Freitas Maneti, Bueno, Marielys Siqueira (Orgs). Hospitalidade: Cenários e oportunidades. São Paulo: Pioneira Thomson Learning, 2003.

CARVALHO, D. S. de. Relatório apresentado ao Exmo. Sr. Dr. Fernando de Melo Viana pelo Dr. Daniel de Carvalho, referente aos anos de 1922 a 1926. Belo Horizonte: Secretaria da Agricultura/Imprensa Oficial, 1926.

CHAVES, Valéria da Conceição. Patrimônio Natural de Ouro Preto (MG): usos e desusos dos atrativos naturais nos roteiros turísticos. Monografia de Conclusão de Curso. Universidade Federal de Ouro Preto. Ouro Preto: MG, 2012.

CNUC. Cadastro Nacional de Meio Ambiente. Ministério do Meio Ambiente. MMA. Disponível em: <http://www.mma.gov.br/areas-protegidas/cadastro-nacional-de-ucs>. Acesso em: 13 jun. 2014.

CONAMA. Resolução n ${ }^{\circ}$ 001. CONSELHO NACIONAL DO MEIO AMBIENTE. Ministério do Meio Ambiente (MMA), Brasília, 1986.

DALE, H. E. Sustentabilidade em um mundo lotado. Scientific American Brasil 41, São Paulo: Duetto. 2005. 
DENCKER, Ada de Freitas. Métodos e técnicas de pesquisa em turismo. São Paulo: Futura, 2004.

DEPARTAMENTO DE INFORMÁTICA DO SISTEMA ÚNICO DE SAÚDE. Informações de Saúde. Disponível em <http://www2.datasus.gov.br/DATASUS/index.php?area=04>. Acesso em: 11 nov. 2014.

DESCARTES, Renê. O Discurso sobre o método. São Paulo: Hemus, 1978.

DIAS, A. C.; MOURA NETTO, B. V; MARCONDES, M. A. P. Trilhas interpretativa do Rio Taquaral: Parque Estadual de Carlos Botelho. Boletim Técnico do Instituto Florestal, São Paulo, p. 11-32, 1986.

DRUMMOND, G. M.; Martins, C. S.; Machado, A. B. M.; Sebaio, F. A. \& Antonini, Y. (orgs.). Biodiversidade em Minas Gerais, um atlas para sua conservação. $2^{\mathrm{a}}$ ed. Fundação Biodiversistas. Belo Horizonte, 2005. 222 p.

HYPKI, C; LOOMIS JÚNIOR, T E. Manual para la interpretacion del ambiente em áreas silvestres. Turrialba: CATIE, 1981, p. (Informe Técnico, 15).

IBGE. INSTITUTO BRASILEIRO DE GEOGRAFIA ESTATÍSTICA. Indicadores De desenvolvimento Sustentável - Brasil 2008. Disponível em <http: //www. ibge.gov .br/home/ geociencias/recursosnaturais/ids/default.shtm>. Acesso em: 08 ago. 2013.

IBGE. INSTITUTO BRASILEIRO DE GEOGRAFIA ESTATÍSTICA. Censo 2010 - Brasil 2010. Disponível em http://www.ibge.gov.br/home/estatistica/populacao/censo2010/>. Acesso em: 08 ago. 2013.

IBOPE. INSTITUTO BRASILEIRO DE OPINIÃO E ESTATÍSTICA. 2009. Disponível em: <http://www.ibope.com.br/calandraWeb/BDarquivos/ sobre_pesquisas/tecnicas_pesquisa.html >. Acesso em: 20 abr 2012.

IMPRENSA OFICIAL MINAS GERAIS (Jornal). Belo Horizonte: Imprensa Oficial do Estado de Minas Gerais. 01/set/1906-31/dez/1907.

INPE. INSTITUTO NACIONAL DE PESQUISAS ESPACIAIS. Monitoramento focos ativos de incêndios. Disponível em: <http://www.inpe.br/queimadas/estatisticas_estado.php?estado $=$ MG\&nomeEstado=MINAS\%20GERAIS >. Acesso em: 20 de nov. 2014.

INMET. INSTITUTO NACIONAL DE METEOROLOGIA. Monitoramento meteorológico anual em Minas gerais. Disponível em: <http://www.inmet.gov.br/portal/index.php?r=clima/webService>. Acesso em: 20 nov. 2014.

LAGE, B. H. G. e MILONE, P. C. Impactos sócio econômicos do turismo. Revista de Administração, São Paulo v.33 n.4, p 30-44, 1998.

LASHLEY, Conrad e MORRISON, Alison (Orgs.) Em busca da hospitalidade: perspectivas para um mundo globalizado. Trad. Carlos David Szlak. Barueri, São Paulo: Manole, 2004.

LINDBERG, K.; HAWKINS, D. E. Ecoturismo: um guia para planejamento e gestão.

São Paulo: Editora SENAC São Paulo, 1999.

MATTA, Roberto da. Você tem cultura? In: Explorações: Ensaios de Antropologia Interpretativa. Rio de Janeiro: Rocco, 1986. Disponível em: 〈http://www.arq.ufsc.br/urbanismo5/artigos/artigos_mr.pdf>

MINISTÉRIO DO MEIO AMBIENTE. Legislação Ambiental, Águas. Disponível em: <http://www.mma.gov.br/legislacao/agua>. Acesso em: 13 jun. 2014.

MINAS GERAIS. Coleção de Leis e decretos. Minas Gerais: Imprensa Oficial, 1892-1897.

MINISTÉRIO DO MEIO AMBIENTE. Resolução CONAMA nº 1 de 23 de janeiro de 1986. Dispõe sobre critérios básicos e diretrizes gerais para a avaliação de impacto ambiental. Disponível em: <http://www.mma.gov.br/port/conama/legiabre.cfm?codlegi=23>. Acesso em: 12 nov. 2014.

OMT. ORGANIZAÇÃO MUNDIAL DO TURISMO. Turismo internacional: uma perspectiva global. 2. ed. Porto Alegre: Bookman, 2003. 
PSF, Programa Social da Família. Entrevista. Ouro Preto-MG, 2014.

RET. Relatório de Estudos Técnicos. Jardim Botânico (PNMA): Secretaria Municipal de Meio Ambiente. Ouro Preto-MG, 2010.

RET. Relatório de Estudos Técnicos. Parque Natural Municipal das Andorinhas (PNMA): Secretaria Municipal de Meio Ambiente. Ouro Preto - MG, 2005.

RFI. Relatório de Focos de Incêndios. $3^{\mathrm{a}}$ CIA.- $3^{\mathrm{a}}$ CIA Corpo de Bombeiros Militar de Ouro Preto. Ouro Preto-MG, 2014.

RFI. Relatório de Focos de Incêndios. Brigada Voluntária de Incêndios B1. Ouro Preto. Ouro PretoMG, 2014.

SERVIÇO MUNICIPAL DE ÁGUA E ESGOTO DE OURO PRETO. Termo de Referência para Contratação de Empresa Especializada para Elaboração do Plano Municipal de Saneamento Básico de Ouro Preto. Versão Preliminar. 2011a.

SANTOS FILHO, C. Pesquisa quantitativa versus pesquisa qualitativa: o desafio paradigmático. In: SANTOS FILHO, C; GAMBOA, S. S. Pesquisa educacional: quantidade-qualidade. 4. ed. São Paulo: Cortez, 2001, p.13-59.

SEGAWA, H. Ao amor do publico: Jardim no Brasil. Studio Nobel/FAPESP, São Paulo. 1996.

SOUZA, M.L. Mapeamento geotécnico da cidade de Ouro Preto-MG (escala 1:10.000) Susceptibilidade aos movimentos de massa e processos correlatos. Dissertação de Mestrado. Escola de Engenharia da USP. São Carlos: São Paulo, v. 2, 1996.

SWARBROOKE, Robert. J. Turismo Sustentabilidade, Gestão e Marketing. São Paulo, 2. Ed. V. 4, ALEPH. 2000.

TEIXEIRA, W. G; SILVA JR, J. P. S. Recuperação de Áreas Urbanas Degradadas. In: Anais. Congresso Brasileiro de Arborização Urbana, 2. São Luís - Ma. 1994. p.155-162.

\section{Recebido em: 04/12/2014 ( $1^{\text {a }}$ versão) $03 / 09 / 2015$ ( $2^{\text {a }}$ versão) $11 / 05 / 2016$ ( $3^{\text {a }}$ versão)}

Aprovado: 20/05/2016

\section{Agradecimentos}

A realização deste trabalho, não teria sido possível sem a colaboração e o apoio de diversas pessoas, entretanto, gostaríamos de expressar o nosso agradecimento especial ao Gestor Municipal e ambientalista Ronald Carvalho Guerra, pela iniciativa de transformar a área do Jardim Botânico em uma Unidade de Conservação, com vistas à preservação do sítio arqueológico e dos recursos hídricos da cidade de Ouro Preto. Bem como pela articulação institucional e coordenação do projeto.

À Bióloga e Geóloga Josefa Clara Lafuente Monteiro pela parceria e co-orientação dos trabalhos.

Aos demais membros da equipe de consultores envolvidos no projeto de cadastramento da UC, a saber, Bernardo Andrade, Historiador; Guilherme Morais, Engenheiro Florestal; Silvia Magalhães, Geógrafa; Eduardo Ataíde, Biólogo. Ao Renato Debrot, pelo estímulo e encorajamento.

Sobretudo, agradecemos ao Edenir Ubaldo Monteiro, Sidnéia Francisca dos Santos, Jurandir dos Santos e à Associação de Moradores do Bairro São Cristóvão pelo acompanhamento às visitas in loco, auxílio essencial para obtenção das informações utilizados no decorrer deste trabalho. 